\title{
Analytical and Clinical Implications of Soluble Transferrin Receptors in Serum
}

\author{
Ellen P. A. Kuiper-Kramer, Carla M. S. Huisman, Jan van Raan and Henk G. van Eijk \\ Klinisch Chemisch Laboratorium, Sophia Ziekenhuis, Zwolle, The Netherlands
}

Summary: In this study the analytical performances of two recently introduced assays for soluble transferrin receptors in serum were tested. The Ramco transferrin assay was compared with the Eurogenetics assay. In a small clinical study serum samples from patients with anaemia of chronic disease, iron deficiency and myelodysplastic syndrome were analysed, as well as sera from healthy volunteers. The analytical performances of the Ramco assay were found to be acceptable. In the Eurogenetics test however, inter-assay imprecision and the end of run drift were unacceptably high.

We were able to confirm that in patients with uncomplicated iron deficiency the concentration of soluble transferrin receptors is higher than in healthy volunteers. In cases of anaemia of chronic and inflammatory disease, the levels of soluble transferrin receptors in serum are slightly, but not significantly, higher than in normal subjects. Measurement of soluble transferrin receptors in serum provides a good differentiation between anaemia of chronic disease and iron deficiency.

\section{Introduction}

Iron is one of the most important elements in the human body. It is essential for cellular growth and metabolism. However, an excess of iron can lead to intracellular damage to DNA and proteins by producing free radicals in combination with oxygen (1). To prevent damage from these radicals iron is transported complexed to transferrin.

The transferrin receptor is a transmembrane protein present in all body cells (fig. 1) $(1,2)$. It consists of two identical domains. Each domain is capable of binding two molecules of transferrin. The affinity of the receptor for transferrin depends on the saturation of transferrin with iron and is especially high for completely saturated transferrin. The number of cellular transferrin receptors depends on the cell's need for iron. The production of the transferrin receptor is regulated on the level of RNA by the intracellular iron content (fig. 2). Depending on this concentration either the iron storage protein ferritin or the transferrin receptor is produced. Various proteins, the so called iron binding proteins, can influence these

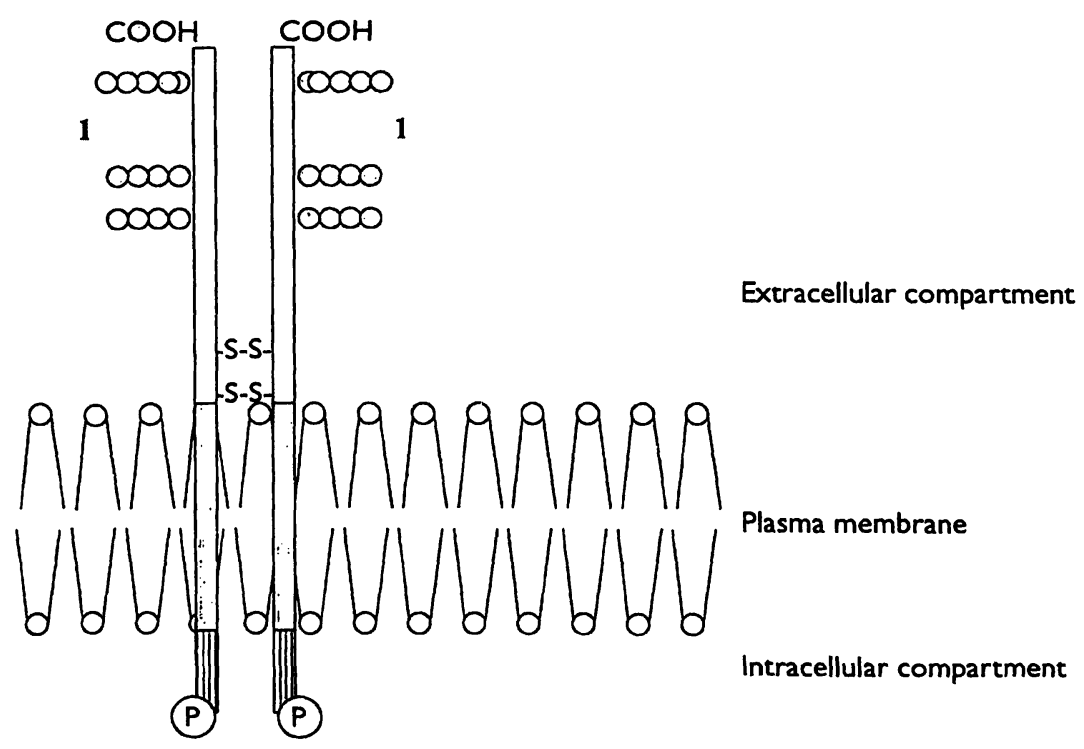

Fig. 1 The transferrin receptor is a dimer of two identical $M_{\mathrm{r}}$ 95000 polypeptides. Each monomer can be divided into

(i) a large extracellular region (empty box) with a number of sugar residues (1) attached to the $\mathrm{C}$-terminal end, (ii) a small and hydrophobic intermediate segment (grey box) that spans the plasma membrane and

(iii) a short cytoplasmic "tail" containing a phosphorylation site (P). 
Intracellular iron concentration low

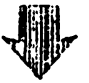

Iron Responsive Element - Binding Protein activity high

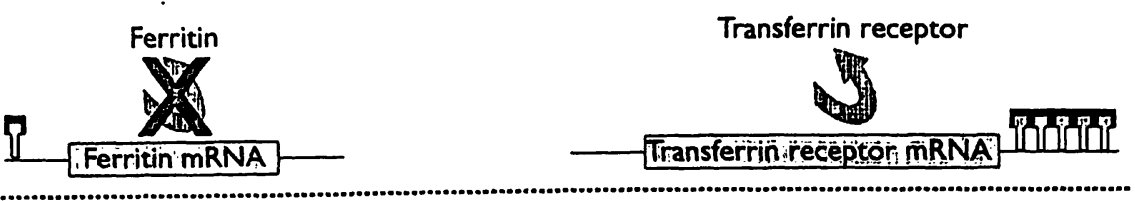

Intracellular iron concentration high

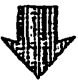

Iron Responsive Element - Binding Protein activity low

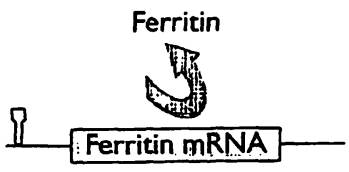

Transferrin receptor

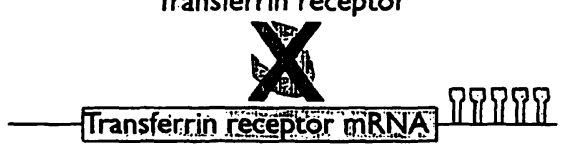

Fig. 2 Schematic presentation of the interaction between the ironresponsive element and the iron binding protein and the effects of Iron responsive element

processes. An excess of iron binding to the iron responsive elements facilitates the translation of RNA coding for the ferritin molecule. In intracellular iron deficiency, a decreased binding of iron to these proteins leads to the translation of that part of the RNA which codes for the transferrin receptor.

Soluble transferrin receptors in serum are found as a truncated fragment of transmembrane transferrin receptors $(3,4)$. The level of soluble transferrin receptors is directly proportional to the total mass of tissue receptors (2). Since most of the tissue receptors can be found on erythroid precursor cells, the number of transferrin receptors in serum is directly proportional to erythroid activity (5). In cases of erythroid hyperplasia, as in iron deficiency and haemolyic anaemia, the level of soluble transferrin receptors is raised. In cases of bone marrow aplasia the level is sharply reduced.

Recently the concentration of soluble transferrin receptors in serum was postulated as a new quantity in the diagnosis of anaemia caused by iron deficiency (5-7). A possible role for soluble transferrin receptors in the differentiation of anaemia of chronic disease from iron deficiency could be expected and has been described $(8-10)$.

In the present study, the analytical performances of two recently introduced soluble transferrin assays were tested. Serum samples from patients with anaemia of chronic and inflammatory diseases, iron deficiency and myelodysplastic syndromes were analysed, as well as sera from healthy volunteers. A bone marrow aspirate was taken from every patient in order to establish the amount of stainable iron, which serves as the gold standard for total body iron stores. this interaction. Depending on the intracellular iron concentration either ferritin or the transferrin receptor is produced.

$n$ Iron responsive element-binding protein

\section{Materials}

Test procedure

The Ramco transferrin receptor kit was obtained from DPC, Apeldoorn, the Netherlands. The Eurogenetics assay was obtained from Eurogenetics, Tessenderlo, Belgium.

Both the Ramco and the Eurogenetics transferrin receptor kits are enzyme immunoassays (EIA) based upon the double antibody sandwich method. They differ in the dilution of the samples and in the incubation time. In the Ramco test, samples are prediluted 100 -fold and in the Eurogenetics assay 10-fold. The incubation time in the Ramco test is one hour and in the Eurogenetics test only 20 minutes. Results are expressed as $\mathrm{kU} / \mathrm{h}$ in the Eurogenetics assay and in $\mathrm{mg} / \mathrm{l}$ in the Ramco test. The assay procedures were followed according to the instructions of the manufacturers.

\section{Apparatus}

Precision pipettes: reference pipettes were obtained from Eppendorf, Germany.

Microplates were washed in a microtitration plate washer 1296024 from Wallac, Finland.

Microtitre plates were analysed in the microplate absorption photometer type ht II from Anthos, Austria.

\section{Patients}

Serum samples and freshly drawn bone marrow aspirates of patients with 3 forms of anaemia were studied. Serum samples were stored at $-80^{\circ} \mathrm{C}$ until analysis. Bone marrow cells were obtained from the sternum or crista iliaca and analysed immediately. The diagnosis of anaemia of chronic disorder, iron deficiency or myelodysplastic syndrome was based on morphological criteria combined with clinical and chemical data. For the diagnosis of anaemia of chronic disorder (17 patients), patients were classified based on the clinical syndrome combined with

a) a low haemoglobin concentration,

b) a low iron content in serum and

c) the classic combination in bone marrow aspirates of high levels of stainable iron in the macrophages of the myelodysplastic syndrome and the absence of iron in erythroblasts. 
Iron deficiency (10 cases) was defined by the combination of

a) a low haemoglobin concentration, low iron content in serum,

b) a low ferritin concentration and

c) morphological criteria like microcytic anaemia and absence of bone marrow iron in morphological staining techniques.

The diagnosis of myelodysplastic syndrome (10 cases) was based on the morphological criteria of the latest French American British (FAB) classification (11). All bone marrow aspirates were judged by a panel of morphologists. Patients diagnosed with chronic myelo-monocytic leukaemia were excluded from the study, as well as patients with refractive anaemia with excess of blasts in transformation (RAEBt).

Serum samples from 62 healthy volunteers were taken as normal controls.

\section{Staining procedures}

Bone marrow aspirates were examined on a slide stained with May Grïnwald Giemsa.

Iron content was estimated by the Prussian blue reaction.

\section{Statistics}

For statistical analysis a Student-test was performed.

Regression analysis according to Passing \& Bablok was performed using commercial software Eval-kit 3.1, CKCHL, Elisabeth Ziekenhuis, Tilburg. The Netherlands.

\section{Methods}

Intra-assay imprecision

To determine the intra-assay imprecision ten replicate measurements on three serum samples were performed.

\section{Inter-assay imprecision}

Duplicate measurements on 3 serum samples were performed in order to determine the inter-assay imprecision. Each sample was analysed in five different assays over a period of five weeks. Each serum was divided into five aliquots before freezing to prevent freeze-thaw instability of the receptor.

Additionally the end of run drift was determined by analysing the same samples in the first wells as well as in the last wells of the microplate (Ramco) or in the last wells of six strips (Eurogenetics).

\section{Analytical sensitivity}

The zero standard was determined ten times along with the set of standards and controls. The lowest detectable transferrin receptor concentration was considered as the mean absorbance of the zero standard plus two times the standard deviation.

\section{Assay linearity}

Serial dilutions of serum samples were measured. Serum samples were diluted with zero standard from 1-fold to 10-fold.

\section{Method comparison}

Regression analysis was performed according to the procedure described by Passing \& Bablok (12).

\section{Reference values}

To find the normal values, 62 sera of healthy volunteers were analysed. The normal range was defined as the mean value $\pm 2 S D$.

\section{Results}

Intra-assay imprecision

In the three samples a mean serum transferrin receptor concentration of $1.9 \mathrm{mg} / 1,6.2 \mathrm{mg} / 1$ and $12.1 \mathrm{mg} / \mathrm{l}$ was found.

Using these samples an intra-assay imprecision of 5.4\%, $3.5 \%$ and $4.5 \%$, respectively, was found in the Ramco assay. In the Eurogenetics assay, variability was $4.7 \%$, $7.4 \%$ and $11.1 \%$, respectively.

\section{Inter-assay imprecision}

Three serum samples were used with a mean concentration of soluble transferrin receptors of $2.3 \mathrm{mg} / 1,6.0 \mathrm{mg} / 1$ and $12.0 \mathrm{mg} / 1$, respectiveliy.

Using these samples, an inter-assay imprecision of $9.0 \%, 5.5 \%$ and $5.4 \%$ was found in the Ramco assay. In the Eurogenetics assay these values were $23.7 \%, 14.7 \%$ and $19.5 \%$. A mean end of run drift of $4.1 \%, 5.5 \%$ and $10.6 \%$ in the Ramco assay and a mean end of run drift of $13.9 \%, 10.9 \%$ and $14.4 \%$ in the Eurogenetics assay were found. In individual runs, the end of run drift after 6 strips could rise to $24 \%$ in the Eurogenetics assay.

\section{Analytical sensitivity}

The detection limits of transferrin receptor are $0.2 \mathrm{mg} / \mathrm{l}$ in the Ramco assay and $31 \mathrm{kU} / 1$ in the Eurogenetics assay.

\section{Assay linearity}

In the Ramco assay the recovery after dilution was $108 \%$ for 1 -fold to 10 -fold diluted samples. In the Eurogenetics assay the recovery was $114 \%$ for 1 -fold and $126 \%$ for 10 -fold dilution.

\section{Method comparison}

Regression analysis showed a linear correlation between both tests; $r=0.863$ (fig. 3).

\section{Clinical significance}

For the Ramco assay we found a normal range of 4.94 $\pm 1.64 \mathrm{mg} / \mathrm{l}$. In the Eurogenetics assay the normal range was $351 \pm 200 \mathrm{kU} / 1$.

We analysed 17 sera from patients with anaemia of chronic and inflammatory diseases, 10 sera of patients with proven iron deficiency and 10 sera of patients with myelodysplastic syndrome; the results are shown in table 1 . In iron deficiency the mean transferrin receptor concentration was significantly higher than in normal subjects. In anaemia of chronic and inflammatory disease the mean concentration was significantly lower than in iron deficiency, and it did not differ significantly 


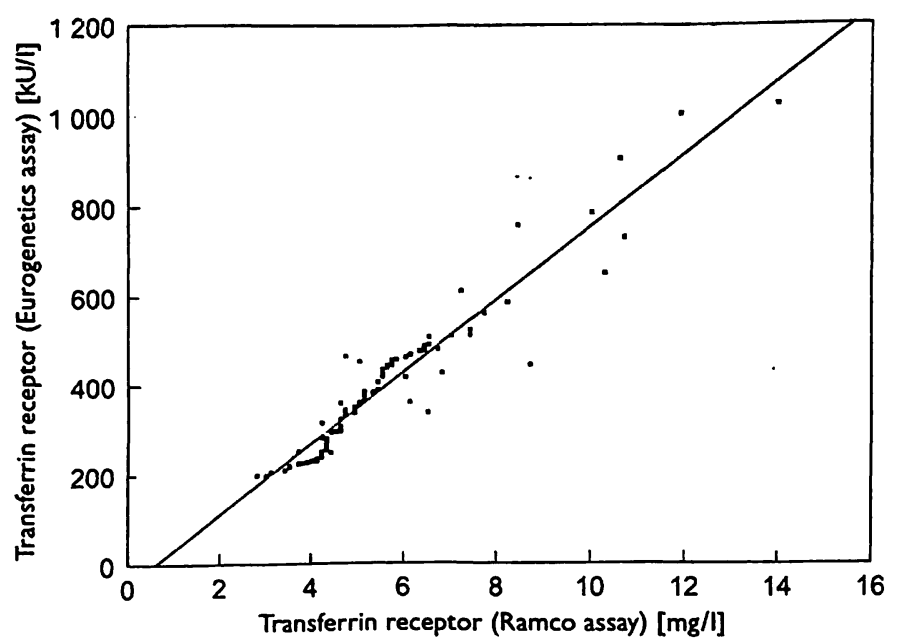

Fig. 3 Method comparison by regression analysis performed according to Passing \& Bablok. Results of the Ramco assay are expressed as $\mathrm{mg} / \mathrm{l}$, the Eurogenetics assay as $\mathrm{kU} / \mathrm{l}\left(10^{3} \mathrm{U} / \mathrm{l}\right)$.

from that of normal subjects. In myelodysplastic syndrome the range was very wide but exclusion of the two most extreme values resulted in a mean concentration which was not significantly different from that of normal subjects.

\section{Discussion}

The analytical performances of two commercially available assays for soluble transferrin receptors in serum were studied. In addition, the clinical significance of the results was assessed. The testkit distributed by Eurogenetics was easier to use than the Ramco assay, but the analytical performances of the Eurogenetics assay were unacceptable. The combination of a high inter-assay imprecision and a high end of run drift makes the assay useless in a routine laboratory, although increasing the incubation time to one hour increasing the dilution of the sample might improve the results. The manufacturer recommends that only 6 strips be tested in one run. However, an end of run drift of $24 \%$ within the first 6 strips was still found. Analysing only 6 strips in one run makes the test much more expensive than the Ramco

Tab. 1 Serum transferrin receptor levels in normal subjects and in patients with iron deficiency, myelodysplastic syndrome and anaemia of chronic and inflammatory disease.

\begin{tabular}{lllll}
\hline Diagnosis & $\begin{array}{l}\text { No. } \\
\text { of } \\
\text { cases }\end{array}$ & $\begin{array}{l}\text { Transferrin } \\
\text { receptor } \\
(\mathrm{mg} / \mathrm{l})\end{array}$ & Range & p-Value \\
\hline Normal subjects & 62 & $4.94 \pm 0.82$ & $3.4-7.0$ & $<0.01$ \\
$\begin{array}{l}\text { Iron deficiency } \\
\text { Myelodysplastic }\end{array}$ & 10 & $12.23 \pm 2.03$ & $10.0-15.8$ & - \\
$\begin{array}{l}\text { syndrome } \\
\begin{array}{l}\text { Anaemia of } \\
\text { chronic disease }\end{array}\end{array}$ & 17 & $5.84 \pm 1.95$ & $3.0-8.7$ & $<0.01$ \\
\hline
\end{tabular}

test because a standard curve has to be established in every run.

The analytical performance of the Ramco assay was better. We found intra- and inter-assay imprecisions that were slightly higher or the same as those given by the manufacturer.

In the Ramco assay the results are expressed in $\mathrm{mg} / \mathrm{l}$, which makes the results comparable to previously published data. In contrast, the Eurogenetics assay express the results in $\mathrm{kU} / \mathrm{l}$. In the past, standardisation of soluble transferrin receptor assays has been problematic, because purified transferrin receptors were not available.

Diagnosis of an uncomplicated iron deficiency is usually straightforward. Serum ferritin is a reliable blood constituent for predicting bone marrow iron stores. Prediction of the iron content in bone marrow from the ferritin concentration in serum is less reliable in inflammatory disease, in cancer, and liver disease. In these cases serum ferritin is often raised as a result of the acute-phase reaction. Serum ferritin parallels other proteins, such as $\mathrm{C}$-reactive, in the acute-phase reaction. Often a bone marrow aspirate has to be taken to establish the diagnosis of anaemia of chronic disease. Therefore it would be valuable to have a new quantity for the differentiation of iron deficiency from anaemia of chronic and inflammatory disease. It has been postulated that the soluble transferrin receptors in serum could be important in this differentiation (8).

In this study we were able to confirm that in patients with uncomplicated iron deficiency the concentration of soluble transferrin receptors is higher than that in healthy volunteers. In cases of anaemia of chronic and inflammatory disease the levels of soluble transferrin receptors in serum are slightly, but not significantly, higher than in normal subjects. By measuring soluble transferrin receptors in serum, a good differentiation between anaemia of chronic disease and iron deficiency is possible.

Another diagnostic problem is caused by anaemia associated with myelodysplastic syndromes. Myelodysplastic syndromes are a heterogeneous group of disorders in which anaemia is often the presenting symptom. In the early phases many patients receive iron to correct their haemoglobin concentration, leading to a delay in diagnosis and accumulation of iron in multiple organs. In this study soluble transferrin receptors in the sera of patients with myelodysplastic syndrome were analysed. The results varied enormously. In most patients normal levels were seen. However, some individual patients showed extremely elevated values, even far above the upper limit found in severe iron deficiency. These results indicate that in myelodysplastic syndrome, investigation 
of the bone marrow is still required for diagnosis, and analysis of the soluble serum transferrin receptor is not helpful.

In conclusion, the results in this study have shown that the analytical performances of the Ramco assay are acceptable, whereas those of the Eurogenetics assay are not. In the latter assay the inter-assay imprecision and the end of run drift are unacceptably high. Using these commercial test kits, the present small clinical study confirms previously published data showing that soluble transferrin receptors in serum are elevated in uncompli-

\section{References}

1. Brock JH, Halliday JW, Pippard MJ, Powell LW. Iron metabolism in health and disease. London: WB Saunders Company Ltd, 1994.

2. Cook JD, Skikne BS, Baynes RD. Serum transferrin receptor. Ann Rev Med 1993; 44:63-74.

3. Chitambar CR, Loebel AL, Nobie NA. Shedding of transferrin receptor from rat reticulocytes during maturation in vitro: soluble transferrin receptor is derived from receptor shed in vesicles. Blood 1991; 78 (9):2444-50.

4. Rutledge EA, Root BJ, Lucas JJ, Enns CA. Elimination of the $\mathrm{O}$-linked glycosylation site at $\mathrm{Thr} 104$ results in the generation of a soluble human transferrin receptor. Blood 1994;83 (2): $580-6$.

5. Kohgo Y, Niitsu Y, Kondo H, Kato J, Tsushima N, Saski K, et al. Serum transferrin receptor as a new index of erythropoiesis. Blood 1987; 70 (6): 1955-8.

6. Skikne BS, Flowers $\mathrm{CH}$, Cook JD. Serum transferrin receptor: a quantitative measure of tissue iron deficiency. Blood 1990; 75 (9):1870-6.

7. Punnonen $\mathrm{K}$, Irjala $\mathrm{K}$, Rajamaki A. Iron-deficiency anemia is associated with high concentrations of transferrin receptor in serum. Clin Chem 1994; 40 (5):774-6.

8. Petterson T, Kiviviori SM, Siimes MA. Is serum transferrin receptor useful for detecting iron-deficiency in anemic patients with chronic inflammatory diseases? $\mathrm{Br} \mathrm{J}$ Rheumatol 1994; $33(8): 740-4$. cated iron deficiency. Measurement of the concentration of transferrin receptors in serum can help in the differentiation of subjects with anaemia of chronic and inflammatory disease from those with iron deficiency. In the diagnosis of myelodyplastic syndrome, the soluble transferrin receptor concentration is of no help, and a bone marrow aspiration is always required.

\section{Acknowledgements}

The authors gratefully thank Dr. W. van Gelder for kindly providing figures 1 and 2 .

9. Feelders RA, Vreugdenhil G, Van Dijk JP, Swaak AJ, Van Eijk HG. Decreased affinity and number of transferrin receptors on erythroblasts in the anemia of rheumatoid arthritis. Am J Haematol 1993; 43 (3):200-4.

10. Ferguson BJ, Skikne BS, Simpson KM, Bayner RD, Cook JD. Serum transferrin receptor distinguishes the anemia of chronic disease from iron deficiency anemia. J Lab Clin Med 1993; $119(4): 385-90$.

11. Bennet JM, Catovsky D, Daniel MT, Flandrin G, Galton DAG, Gralnick HR, et al. Proposals for the classification of the myelodysplastic syndromes. Br J Haematol 1982; 51:189-99.

12. Passing $H$, Bablok W. A new biometrical procedure for testing the equality of measurements by two different analytical methods. J Clin Chem Blin Biochem 1983; 11 (21):709-20.

13. Bowen DT, Culligan D, Beguin Y, Kendall R, Willis N. Estimation of effective and total erythropoiesis in myeloplasia using serum transferrin receptor and erythropoietin concentrations, with automated reticulocyte parameters. Leukemia 1993; 8 (1):151-5.

Received February 12/May 8, 1996

Corresponding author: P. A. Kuiper-Kramer, Sophia Hospital, PO Box 10.400, NL-8000 GK Zwolle, The Netherlands 
, 